\title{
Narrativa i pedagogia: un assaig entre l'ètica, l'acompanyament i la cura
}

\author{
Mercè Cols Catasús* \\ Anna de Monserrat Vallvè*** \\ Mariona Dalmau Montalà
}

Resum

Aquest article posa de relleu les aportacions a l'ètica del mestre realitzades per una selecció de pensadors que van de la pedagogia clàssica fins la contemporània. Es fa un repàs de la presència de la dimensió ètica en els textos pedagògics d'autors de referència de la nostra cultura educativa per tal de veure com aquesta és una qüestió nuclear entre les aportacions que han fet els grans mestres i pedagogs, així com destacar la importància de l'ètica cristiana en la pedagogia sense que això sigui excloent de cap altra pedagogia. A través d'aquest recorregut, s'aporten elements per a la reflexió i l'anàlisi amb la intenció que ens ajudin a bastir la formació inicial dels mestres a la universitat i que aquesta contribució genuïna de la pedagogia sigui un element configurador de I'itinerari de formació dels mestres.

\section{Paraules clau}

Ètica, pedagogia, cura, acompanyament, persona, compromís, formació de mestres.

Recepció original: 15 d'abril de 2017

Acceptació: 15 de setembre de 2017

Publicació: 20 de juliol de 2018

\section{Introducció}

Aquest article presenta un recorregut per la història del pensament a través dels pedagogs, tant els anomenats clàssics com els contemporanis i coetanis nostres, per tal d'extreure'n les aportacions ètiques, amb la intenció que esdevinguin uns referents tant per repensar des d'aquesta perspectiva l'educació actual com per incorporar-los en la formació de futurs mestres i en l'exercici professional en l'àmbit de tota la comunitat educativa.

L'objectiu del treball és el de bastir la formació dels futurs mestres fent un repàs de la presència de la qüestió ètica en la història de la pedagogia per tal de posar en evidència que aquesta n'és una qüestió central, tal i com ens mostren les aportacions d'una selecció de grans mestres de la història de la pedagogia com Sòcrates, Plató,

$\left(^{*}\right)$ Professora de l'Àrea d'Humanitats dels estudis d'Educació de la Facultat de Psicologia, Ciències de I'Educació i de l'Esport Blanquerna-URL. Llicenciada i Doctora en Pedagogia per la Universitat de Barcelona i diplomada en Magisteri per la Universitat de Barcelona. Adreça electrònica: mercecc@blanquerna.url.edu

${ }^{* *}$ Professora dels estudis d'Educació de la Facultat de Psicologia, Ciències de l'Educació i de l'Esport Blanquerna-URL. Doctora en Pedagogia per la Universitat Autònoma de Barcelona. Llicenciada en Pedagogia per la Universitat de Barcelona i diplomada en Magisteri per l'Escola de Mestres Blanquerna. Investigadora del Grup de Recerca PSITIC (Pedagogia, Societat i Innovació amb el suport de les Tecnologies de la Informació i la Comunicació). Adreça electrònica: annamv@blanquerna.url.edu

$\left.{ }^{* * *}\right)$ Professora dels estudis d'Educació de la Facultat de Psicologia, Ciències de l'Educació i de l'Esport Blanquerna-URL. Doctora en Psicologia per la Universitat Ramon Llull. Llicenciada en Psicologia per la Universitat de Barcelona. Investigadora-col-laboradora del Grup de Recerca Psicologia, Persona i Context: Infància i investigadora del grup DISQUAVI (Discapacitat i qualitat de vida: Aspectes Educatius). Adreça electrònica: marionadm@blanquerna.url.edu 
Aristòtil, sant Ignasi de Loiola, Montaigne, Rousseau, Dewey, Xirau, sant Joan Bosco, Montessori, Decroly, Sensat, Korczak, Freinet, Vergés, Malaguzzi, Freire, Milani, Illich, Van Manen, Meirieu, Hansen i Tonucci. Per a aquesta fita, i seguint la proposta de Fullat (2005), hem recorregut històricament a textos de diversos pedagogs que són significatius per tal de fornir la formació actual dels mestres partint de les seves aportacions en el camp de l'ètica.

Per fer-ho, també hem integrat l'experiència d'entrar novament en contacte amb cadascun dels pedagogs, realitzant una nova i fecunda hermenèutica que ens ha permès establir un nou diàleg diacrònic entre nosaltres i els pedagogs al llarg del temps, $i$ sincrònic entre nosaltres i el món educatiu actual, una nova fusió d'horitzons. Ens hem adonat de la vàlua d'aquest exercici i de la necessitat que hi ha, en tot procés de reflexió i d'autoreflexió, de retornar a les fonts primàries i originàries que ens ajuden a formular el sentit del que fem.

El primer que hem descobert a través de la relectura d'aquests pedagogs és que tots, explícitament o implícita, situen el respecte per l'ésser humà en el nucli de la qüestió ètica, tant si es tracta d'un infant, d'un jove, del mestre i de la relació que s'esdevé entre ells per assolir el fi de l'educació. Al llarg del recorregut, els autors van posant de manifest que res no tindrà un sentit ètic si no situem al bell mig el valor de l'ésser humà, la persona amb totes les seves dimensions; la qual cosa hauria de ser el principi i la fi de l'educació.

\section{Educar com a esdeveniment ètic}

La influència que han tingut les cultures grega, romana, judaica i cristiana en el pensament occidental i que, al seu torn, han influït considerablement en el pensament actual sobre l'educació ens ajuda a comprendre la realitat des de la tradició per albirar el futur (Fullat, 2005, p. 496). En aquest sentit, si tenim la pretensió de destacar el plantejament ètic que ha de tenir avui l'educació, ens cal recórrer a les bases de la nostra cultura cristiana i a les seves arrels més profundes atès que, en gran part, en som hereus. Igualment, la filosofia i especialment la filosofia clàssica, serà el marc idoni per comprendre la incidència que ha tingut el pensament filosòfic de cadascuna d'aquestes cultures en la pedagogia. De fet, la filosofia ha representat la manera d'entendre la vida i de viure de cada cultura, per la qual cosa és important tenir en compte que el cristianisme és molt més que una manera de viure. Segons Ferrater Mora, «només el cristianisme proporciona a I'home la possibilitat d'una vida» (1961, p. 123) a De la Arada, Vilanou i Carreño (2014).

Entre els diversos llegats que ens ha deixat l'hel-lenisme sobresurt el que té a veure amb la seva dimensió pedagògica. Sobre aquest punt, els mateixos autors destaquen que «els grecs van perfilar la seva aventura cultural i espiritual com un sistema formatiu, entès com a paideia, que tenia com a objectiu prioritari el cultiu de l'ànima». Veiem que aquesta paideia grega és entesa com un valor educatiu que contempla, de manera prioritària, la persona en la seva dimensió més profunda quan indiquen que en l'actiu de la paideia grega s'hi situa «el seu valor educatiu i la intenció d'implantar entre els joves un sentit de decòrum (perfil estètic) i d'honestedat (caràcter ètic)» (p. 28). Aquests mateixos autors deixen ben clar que «l'hel-lenisme i el cristianisme s'han influenciat mútuament i que la paideia cristiana és pot considerar una fusió entre la tradició grega, romana i jueva, i que d'aquesta fusió va sorgir el domini cristià que té com a valor la 
caritas (amor) que inunda l'univers fins a l'extrem que tot s'alimenta d'aquest valor» ( $p$. 40). Si es compara entre l'amor (eros) de la cultura grega i l'amor (caritas) del cristianisme és obvi que es tracta de plantejaments diferents. Per tant, es poden considerar dos tipus d'amor distints i que cadascún d'ells té una dimensió pedagògica específica «l'amor centrípet i racional de l'eros de la paidèia grega i l'amor centrífug i personal de la pedagogia cristiana que exalta el valor del proïsme. El primer amor s'articula al voltant del jo i, per tant, de l'egoisme, el segon amor -el que correspon a l'àgape o caritas cristiana- ho centralitza tot en el proïsme de manera que l'alteritat genera el sentiment de compartir desinteressadament a través d'una fusió entre els que s'estimen» (De la Arada, Vilanou i Carreño, 2014, p. 41-42).

De la mateixa manera, recordem que en el seu testament pedagògic publicat l'any 1826 i que porta per títol El cant del Cigne, Pestalozzi deixa palesa una veritable filosofia de l'acte pedagògic: "L'acte pedagògic es desenvolupa sobre un fons d'amor, que teixeix el llaç universal dels homes entre ells, però també sobre un fons de fe, que imposa el respecte de la particularitat de cadascú i del seu esdevenidor en llibertat: Liebe und Glaube (amor i fe)» (Söetard, 1995, p. 57). Aquest és el missatge últim de Pestalozzi.

Des d'aquesta perspectiva també ens hem preguntat la idea d'ètica de la qual partim en el nostre estudi, tot considerant que l'entenem com la resposta a una situació concreta que demana un posicionament de l'ésser humà.

És clar que concebem la pedagogia com una disciplina d'excel.lència perquè ens orienta sobre el valor, el significat i la naturalesa del fet d'ensenyar i d'educar adreçat a l'infant o al jove en el seu ser i en el seu «arribar a ser». I aquesta orientació ve motivada per l'interès envers l'altre, que pot ser un infant, un jove o un adult. Podríem dir que si l'amic es guia per l'amistat, el mestre es guia per la pedagogia, intentant respondre a través dels seus actes i les seves accions a la pregunta sobre què és l'educació o què significa estar guiat per la pedagogia.

Alhora, ens fem càrrec que el significat concret de la pedagogia, així com el de l'educació i la formació, tan sols es pot discernir des de la concreció de la vida real, tan sols es troba en l'experiència de la seva presència i, partint d'aquest supòsit, considerem l'acció educativa com quelcom complex i alhora subtil, que ha d'incorporar la capacitat de distingir activament el que és apropiat d'allò que no ho és per als infants o els joves, l'esdeveniment ètic, mostrant alhora formes possibles de ser i d'estar en el món. I aquesta mena d'acció educativa, des del significat que hem exposat, hauria de ser una acció conduïda per l'ètica, en paraules de Van Manen, una acció de tacte com a «forma manifesta de respondre i que emergeix de l'educador en la seva manera de veure, escoltar i reaccionar davant les situacions educatives, i que posa en relació el que és amb el que fa com a docent i com a educador» (Van Manen, 1998, p. 46). Per Van Manen, la responsabilitat ètica-pedagògica del professorat té a veure amb el compromís apassionat dels educadors vers els estudiants. Ho deixa ben palès quan assenyala que les condicions de la pedagogia són: l'amor i l'afecte, l'esperança i la confiança i la responsabilitat (Jordán, 2015). En aquest sentit, Van Manen ens parla del valor de la sensibilitat dels vertaders educadors vers l'alumnat i explícita quan diu: «su inclinación pedagógica hacia sus alumnos está siempre animada por el amor más sincero hacia ellos» (1998, p. 47). Aquesta sensibilitat forma part de la vàlua personal del professor, com «El verdadero profesor -no el simple técnico o el asalariado de la enseñanza- capta con fina sensibilidad las continuas necesidades de todos y cada uno de sus alumnos y se ve 
impelido a responderlas haciéndose cargo de cada uno en concreto. (...) resultándole imposible así adoptar una actitud de superficial de "indiferencia"» (Jordán, 2015, p. 383).

Al seu torn, Meirieu defineix l'ètica com «[...] La interrogación del sujeto sobre la finalidad de sus actos. Interrogación que les sitúa, de entrada, ante la cuestión del Otro' ..., ya que la existencia del Otro, cada vez que yo actúo, en el sentido propio del término, plantea "una cuestión": ¿le reconozco como tal, en su alteridad radical, o acaso hago de él el objeto de mis manipulaciones para que sirva a mi satisfacción? En todo lo que digo, en todas las decisiones que tomo, en el seno de las instituciones que frecuento, ¿permito al Otro que sea, frente a mí, incluso contra mí, un Sujeto? ¿Acepto ese riesgo, a pesar de las dificultades que ello comporta, de la incertidumbre en la que me sitúa, de las inquietudes que surgirán inevitablemente a cada paso?...esta es, para nosotros, la cuestión ética fundamental»(Meirieu, 2001, p. 10). Aquesta idea es concreta també a Frankenstein educador, en què l'autor qüestiona la concepció de l'educació com a projecte de domini de l'educand i de control del seu destí, com el que va esdevenir en el terreny de la ficció a Frankenstein, a Pinotxo, a l'estàtua de Pigmalió o a d'altres, tot afirmant que aquesta perspectiva condueix a un fracàs destructiu (Meirieu, 1998).

Tenint en compte que la concepció ètica que Aristòtil defensa en l'Ėtica Nicomaquea és d'ordre pragmàtic i s'oposa de manera radical a l'intel-lectualisme de Sòcrates i Plató, la virtut aristotèlica no consisteix en el coneixement, ans en l'hàbit, en la pràctica, en una disposició i inclinació de la voluntat. En aquest sentit, ens alineem amb Aristòtil pel fet que no perseguim en els futurs mestres una metafísica de la moralitat, sinó una anàlisi de la praxi humana tal com es presenta en la realitat.

Així, en l'ètica aristotèlica, les virtuts del caràcter no consisteixen en el coneixement en el sentit d'un saber cognitiu. Al contrari, la virtut és un hàbit, una disposició, una inclinació constant de la voluntat. D'aquesta manera, Aristòtil no persegueix una metafísica de la moralitat, sinó una anàlisi de la praxi humana tal com es presenta en la realitat. El fragment que presentem a continuació resulta il.lustratiu de la idea que s'intenta plasmar: «...con respecto a la virtud no basta con conocerla, sino que hemos de procurar tenerla y practicarla...» (Aristòtil, 2007, 1179b, p. 1-3), «... un hombre es prudente no sólo por saber sino por ser capaz de obrar...» (Aristòtil, 2007, 1152a, p. 10).

Diferentment, l'ètica platònica es construeix sobre els pilars de la concepció de la felicitat i de la virtut. Escriu Plató: «Car quan sento parlar sobre la virtut o sobre alguna altra ciència un home que és en realitat un home i és digne dels seus discursos, sento

(1) Quan Meirieu parla del «Otro» (en majúscules), es refereix a un ésser que assumeix la seva alteritat; evoca una llibertat que està en joc; una persona que gosa parlar per ella mateixa sense sotmetre's a la pressió social, a la influència del més fort o bé de qui és més influent, o a la inquietud per conformar-se o estar disconforme. En canvi, quan Meirieu parla del «otro» (en minúscula), designa tan sols un ésser humà a qui es pot tractar com un objecte, que es pot decidir per ell, seduir-lo i donar-li forma, i que podem considerar com a fruit del resultat de les influències rebudes. En aquest sentit podríem dir que quan parlem d'educació ens referim a l'Altre i, en canvi, quan parlem d'adoctrinament ens referim a l'altre.

Proposem, doncs, el camí de la formació ètica com a fascinació per la transformació de l'altre; d'aquest altre que és enmig del camí o al marge del camí, com una «relación de acción práctica entre un adulto y un joven que está en camino de la vida adulta». Proposem també el camí de l'educació com a relació ètica des de la interrogació de la persona sobre la finalitat d'allò que fa a la seva vida; desviant-nos, així, de la moral entesa com a afirmació, com a conjunt de normes socials que fan referència al comportament dels individus en una organització determinada i segons uns valors determinats. És, per tant, en aquest sentit, un treball obert a la interrogació constant. 
una joia profunda perquè veig que qui parla i els mots que diu convenen i s'acorden uns amb altres; i em sembla el músic perfecte perquè produeix l'harmonia més bella, no amb la lira ni amb un altre instrument frívol. Un home així em sembla viure la seva vida, fent acordar les paraules amb els fets (...)» (Plató, 1924, 188 c-e., p. 120).

De l'ètica socràtica, en podem aprendre que tota ètica comença per un exercici d'autoconeixement: «Coneix-te a tu mateix». Sòcrates creu que l'autoconeixement és l'inici del camí cap al veritable saber. Pensa que coneixent-nos en profunditat adquirim la virtut, és a dir, ens fem bons i feliços. Per ser feliç, un s'ha de conèixer i portar una vida virtuosa i excel-lent. La seva preocupació és impulsar i desvetllar l'impuls per a la recerca personal i la veritat, el pensament propi i la veu interior. La virtut -areté-, en aquest cas, és el comportament adequat a aquella finalitat per a la qual una cosa està feta, és a dir, el comportament adequat a la naturalesa.

A fi de conrear aquest exercici d'autoconeixement, val la pena d'assenyalar com a Sòcrates el va interessar, sempre, mantenir un diàleg viu i amistós amb els seus deixebles, i això requeria una interacció, una comunicació i una obertura a l'altre, etc.; i, a través del seu mètode maièutic, exhortar-los mitjançant la indagació i la ironia per tal que aconseguissin el saber per ells mateixos, gràcies a la dialèctica i a un tracte més individualitzat amb els deixebles.

En el procés educatiu, en el procés d'ensenyar i aprendre, els agents més importants són l'infant i el mestre, en què se situa el nen, l'infant, en el centre de la relació pedagògica. Entre ambdós agents hauria d'existir una relació basada en la confiança per tal endegar, per part de cadascú, un procés de reconeixement de l'altre. Justament, de Don Bosco (1987) ${ }^{2}$-sacerdot i impulsor de l'ordre dels salesians- podem parlar d'una pedagogia de la confiança, en el sentit que sense confiança no hi ha educació en profunditat. Només amb una confiança i familiaritat entre l'educador i l'educand es pot fundar una relació d'autoritat. Aquesta confiança s'instal.la entre ambdós a través de I'afecte; és a dir, quan es posa en el centre de la relació educativa l'esfera de la relació afectiva. Sense afecte no hi ha confiança i sense confiança no hi ha educació. Ell mateix ho afirma quan diu «No basta que los jóvenes sean amados, sino que es necesario que ellos mismos se den cuenta de que son amados» (Cian, 1987, p. 36 i 40).

Per la seva maduresa i pel seu compromís inherent amb la professió d'educar, ha de ser l'educador qui prengui la iniciativa d'apropar-se a l'educand per tal de conèixer-lo bé i descobrir la seva singularitat. En aquest sentit, diu Siguan: «Cal que el mestre sàpiga en tot moment allò que hi ha en el deixeble de valor peculiar i com ha d'obtenir la plenitud del seu desenvolupament» (Xirau, 1986, p. XXXIII). Aquesta singularitat en evolució li ve donada per la seva pròpia història personal, viscuda en un context determinat i que també es troba en constant transformació. Entenent que el mestre ha de ser un professional que estima i té cura de l'infant, el filòsof i pedagog català ho sintetitza d'aquesta manera: «Educar és estimar». El nucli de l'educació és la relació pedagògica, que és intersubjectiva, és una relació interpersonal entre dos éssers humans. I per això l'acció educativa del mestre necessita una voluntat explícita de sentir-se'n responsable i

(2) El seu mètode educatiu serà el Sistema Preventiu en l'educació de la joventut. Cal entendre «preventiu» en el sentit de prevenir el nen o el jove dels perills als quals poden ser sotmesos i orientar-los a definir la vida vers un futur millor. 
d'exercir aquesta responsabilitat en tot el llarg procés d'acolliment i d'acompanyament que té lloc a l'escola.

Des d'una perspectiva rousseauniana, ser mestre significa posar en marxa un procés d'humanització, en el qual el mestre indueix una petició i una exigència vers el seu alumne. L'alumne aprendrà a fer-se home en contacte amb el seu mestre, i, per tant, aquest és sempre un model a seguir. I perquè això sigui possible, el mestre hauria d'actuar des d'una experiència viscuda $i$ sentida, i testimoniar-la en el seu ser i fer d'educador. Això implica que el mestre hauria de tenir clara i assumir quina és la significació, quin és el sentit ètic que configura i dóna a la seva feina d'educar. "Si no amo el mundo, si no amo la vida, si no amo a los hombres, no me es posible el diálogo» (Freire, 2005, p. 107).

L'educació sovint es defineix com un art. «La missió del mestre és en el sentit més pur i autèntic una missió artística. És artista de la més delicada de les arts, l'art de la vida en la seva íntegra i harmònica totalitat» (Xirau, 1986, p. 8). En aquest sentit, l'ensenyament ha de despertar la capacitat d'admiració de l'ésser humà. I d'aquí neixen l'esperit crític i artístic. Perquè no es frustri aquesta capacitat, l'educació ha de ser un art. Un art que, per part del mestre, cal anar conreant i cultivant. I això requeriria, entre d'altres, desplegar un treball de la seva interioritat (viure el món interior): la construcció d'una identitat madura, d'un esperit crític i l'àmbit de la llibertat, el treball de la voluntat per canviar, la disposició del cor, la sensibilitat pedagògica, l'orientació de la mirada; en definitiva, fer créixer «la finor espiritual» com a docent.

I, alhora, ajudar el docent en el procés d'exploració i de reflexió sobre el que un fa no solament sobre les idees sinó també sobre l'experiència- per tal que el pensament que sosté la seva acció esdevingui cada cop més pregon i abundant i, ensems, coherent. I l'educació és un art que implica una vocació de qui desitja exercir-la i posar-la al servei dels altres. Hansen (2001) sosté que la vocació descriu un treball que implica un servei per als altres i una satisfacció en el compliment d'aquest servei. A més a més, considera que la vocació no és una devoció desinteressada, ans té un valor social i proporciona un significat personal de durada.

De la mateixa manera, llegir el pensament de Milani expressat a Experiencias pastorales il.lumina la idea que volem transmetre: «Con frecuencia me preguntan los amigos cómo hago para llevar la escuela y cómo hago para tenerla llena. Insisten en que escriba un método, que les precise los programas, las materias, la técnica didáctica. Se equivocan de pregunta. No deberían preocuparse de cómo hay que hacer para dar escuela, sino de cómo hay que ser... ¡No se puede explicar en dos palabras!.... Hay que tener las ideas claras respecto a los problemas sociales y políticos. No hay que ser interclasista, sino que es preciso tomar partido. Hay que arder del ansia de elevar al pobre a un nivel superior. No digo ya a un nivel igual al de la actual clase dirigente. Sino superior: más humano, más espiritual, más cristiano, más todo» (Milani, 2004, p. 172). Igualment, s'hauria de preveure un treball sobre la confiança amb un mateix i amb els altres; una confiança que serveixi per arrelar-se a les pròpies conviccions i als actes que se'n deriven, així com al món en què li ha tocat viure i treballar.

Durant el periple formatiu dels futurs mestres cal ser conscients que l'acompanyament que se'ls fa, des de la universitat, és un acompanyament durador en el temps. Un acompanyament «vinculat a un exercici de l'amor, i que només adquireix la 
dignitat de mestre aquell que és capaç de consagrar-se amorosament als seus deixebles.» (Xirau, 1986, p. 21). Per anar construint el sentit i la seva identitat com a docents, perquè arribin a madurar i a implicar-se en els canvis, cal establir una relació pedagògica intensa i amb un caliu adequat que demana un quant temps per a sedimentar i proporcionar sentit a tot allò que van interioritzant i que configura la seva vocació. En el nostre cas, com a professors universitaris, entenem que «el paper de l'educació és despertar, promoure, guiar i orientar una vida en el sentit de la pròpia vocació. I trobar la vocació és trobar la llibertat.» (Xirau, 1986, p. 21). Una vocació que, com hem assenyalat més amunt, entén aquesta feina com un servei per als altres i que al mateix temps dóna al futur mestre un sentit d'identitat i de significació.

Les aportacions de Xirau, quan exposa quines són les idees fonamentals d'una pedagogia, il.luminen el que volem transmetre: que «l'escola de la vida, per la vida i per a la vida, en la qual l'educand no sigui un simple recipient on abocar un contingut de fórmules esquemàtiques i mortes, sinó un ésser viu en el qual la natura i l'esperit guarden les virtualitats més pures. (...) La missió del mestre no és altra que fecundar aquests gèrmens virginals i posar-los en les condicions de la més exuberant fructificació.» (Xirau, 1986, p. 77). I encara més, seguint el mestre, quan concreta què és la pedagogia manifesta: «Per això, en el cas concret de l'escola, l'essencial no és el mestre, sinó l'alumne tot mestre digne d'aquest nom és deixeble dels seus deixebles i de si mateix-, i en tota comunitat humana, el mestre sorgeix de manera espontània i natural sense necessitat de tarimes ni de càtedres -per exemple, no apareixen les universitats com una congregació de professors que cerquen alumnes, sinó com una comunitat d'alumnes que busquen un professor.» (Xirau, 1986, p. 107-108). En aquest sentit, Siguan explicita l'arrel d'aquesta concepció pedagògica del filòsof i pedagog català; diu així: "L'actitud amorosa és la que permet al mestre de descobrir les potencialitats úniques del deixeble, de cada deixeble en concret, i la manera d'ajudar-lo a trobar del seu propi camí, aquell que ha de portar-lo a realitzar aquestes possibilitats intransferibles. I és aquesta actitud amorosa la que farà que la persona estimada, en aquest cas l'alumne, contempli amorosament la realitat i descobreixi noves dimensions en la seva vida. De la mateixa manera cal posar en relació la tasca educativa amb l'actitud amorosa.» (Siguan, 1986, p. XLII i ss).

Per tot el que hem dit fins ara, entenem que educar és un esdeveniment ètic. Hem vist com alguns mestres i pedagogs -sota la influència de l'itinerari provinent de Jerusalem- pensen la relació pedagògica des de l'empatia amb l'altre, amb un respecte a l'alteritat. Vilanou ens ho explicita amb les següents paraules «Por su parte nuestro J. Xirau -bajo la influencia del ordo amoris de San Agustín, reactualizado por Scheler- nos narró en Amor y mundo -obra gestada justamente en los años de la Guerra Civil española- la aventura del cristianismo, situando la educación en una senda pedagógica que partiendo de Platón y San Agustín, llega a la Modernidad a través de San Francisco de Asís y Ramón Llull y que insiste en la prioridad del amor cristiano (Charitas), con la consiguiente superación de amor egoísta.» (Vilanou a Fullat, 2005, p. 20).

\section{L'educació com acompanyament i cura}

Cada estudiant arriba a la universitat amb un bagatge personal important que configura, en bona part, la idea que té de si mateix, la seva manera de relacionar-se amb els altres i la intenció amb què s'aproxima a la formació del que molt probablement serà la seva professió. Aquesta manera de ser, de sentir i de conviure és el resultat de les seves 
vivències més emocionals al llarg dels anys anteriors a la seva formació universitària. Entre aquestes vivències hi ha les viscudes en el marc de la pròpia família i dels diferents centres educatius en què ha cursat els estudis que li han permès arribar a la universitat.

En ocasions, la base ètica implícita en moltes d'aquestes experiències s'allunya de les que sostenen el model de mestre que es proposa a la universitat. En aquests casos, l'estudiant no pot donar significat a bona part de les experiències que té en el nou context de formació; no les pot reconèixer com a prioritàries en la seva formació i, fins i tot, les pot arribar a rebutjar buscant altres experiències que li generin menys desconcert i que les pugui reconèixer des de les seves experiències anteriors.

És justament en aquests casos en què el professorat universitari haurà de tenir més cura i més paciència per tal d'intensificar de manera explícita el seu testimoni ètic com a educador i com a persona. De ben segur que l'estudiant després d'un temps d'un cert desequilibri generat per experiències diverses, però d'haver tingut el mestratge d'un professorat amb un estil de ser i de fer de mestre concret, podrà donar sentit a les accions i a les pràctiques universitàries. Acompanyar-lo des del compromís ètic en el seu particular procés de desaprendre i d'aprendre de nou la manera d'enfrontar-se al món ha de ser la responsabilitat del professorat universitari. Només així es podrà garantir que els estudiants puguin construir la seva formació personal i professional fonamentada en l'ètica.

Resulta molt il.lustrativa l'aportació que fa Standing quan explica la transcendència que Maria Montessori tenia en els mestres quan assistien als cursos de formació que feia la pedagoga italiana: «Muchos maestros vinieron (...), llegaron con la intención de aprender a ayudar al niño en su desarrollo y, para su sorpresa, se encontraron que inesperadamente les estaba ayudando en su propio desarrollo. (...) experimentaron una auténtica transformación de mente y alma, y se supieron al final del curso, diferentes y mayores que en un principio. Se dieron cuenta de que habían hecho una inversión espiritual que les redituaría intereses mientras vivieran, porque la vida había adquirido un nuevo sentido» (Standing, 1985, p. 4). En aquest sentit, cal que la universitat potenciï la vessant formativa per sobre de l'instructiva.

Per això, cal reconèixer que durant el procés de formació d'un mestre, hi ha alguna cosa que s'escapa de l'avaluació i del control que puguin fer els seus formadors. Hi ha quelcom més intangible i que té a veure amb allò que popularment anomenem la «fusta de mestre». Montaigne ${ }^{3}$, en parlar del tipus de preceptor que li buscava el seu pare, assenyala dues característiques o trets prioritaris que hauria de tenir: bondat $\mathbf{i}$ facilitat de caràcter. I subratllava que la finalitat a assolir per part de l'educand era la següent: portar l'ànima plena i haver-la engrandit, en les seves pròpies paraules: «Hauria de portar l'ànima plena i només la porta embotida, I'ha inflada simplement en lloc d'engrandir-la» (Montaigne, 2012, p. 10). Això és el que semblantment hauríem d'assolir en el procés formatiu a Magisteri, ajudar els futurs mestres a engrandir l'esperit i a conrear l'ànima de bonesa i bon fer per tal que, en la seva pràctica docent, aquesta sigui d'una bona fusta, així s'evitaria que tinguin «la memòria bastant plena, però el judici completament buit» (Montaigne, 2012, p. 12).

(3) Fou molt crític amb l'estil educatiu de la seva època (segle xvl), que se sostenia exclusivament sobre el treball memorístic i que menystenia el treball de l'àmbit de la raó i de la consciència. 
Des de la perspectiva en la què abordem el procés formatiu, entenem que tot acompanyament implica tenir cura de l'altre. En termes de la tradició de l'espiritualitat ignasiana fundada per Sant Ignasi de Loiola, la cura personalis és una expressió llatina que podem traduir per «atenció integral a tota la persona». L'expressió suggereix una atenció individual i singular a les necessitats de cada ésser humà, que difereixen en cada cas en relació amb la seva circumstància única i amb els propis objectius, els reptes, els canvis, les necessitats i les dificultats de cada persona. L'expressió té el segell ignasià des de fa més de 500 anys, tot i que posseeix una llarga tradició que es remunta al món hel-lenístic (Pavie, 2010). En la tradició ignasiana i la seva expressió en els Exercicis espirituals ${ }^{4}$, fets i escrits a Manresa (Casanovas 1930, p. 149) pel fundador de la Companyia de Jesús, la cura personalis se significa des de la responsabilitat que s'atorga al superior dels jesuïtes en l'atenció integral de cadascuna de les persones que formen part de la seva comunitat, atenent els talents, els reptes, les necessitats i les possibilitats de cadascuna d'elles. En línies generals, actualment, sovint s'aplica a la consideració de la relació educativa entre mestres i alumnes, sobretot entre aquells que treballen en entorns acadèmics i educatius.

Així, ens trobem que l'expressió té inicialment connotacions espirituals, més concretament és considerada una de les característiques pròpies de l'acompanyament espiritual i també de l'educació i de la formació jesuítica, i que acaba derivant a l'educació i a la formació en general. Per atendre la seva intenció originària, convé destacar que P. Peter-Hans Kolvenbach (2007) descriu la cura com la relació d'ajut d'un company de ruta, i l'adjectivació de personalis atenent que la ruta que hom fa o refà sempre és un camí en solitari; és un camí que cap altra persona pot fer en comptes d'un mateix. En les anotacions ${ }^{5}$ dels Exercicis espirituals, el fundador de la Companyia de Jesús considera que calia precisar la relació, en termes de cura, entre Ignasi -o l'acompanyant dels exercicis- i la persona exercitant.

En aquestes anotacions es defineixen les línies i els aspectes més importants d'aquesta relació, que delimitem en els paràgrafs que segueixen: s'insisteix en el caràcter personal de la relació; aquesta cura es manifesta en els actes humans de «donar» i «rebre», en un acte de transmissió i de recepció en una relació directa entre qui dona i qui rep. No es tracta, doncs, de transmetre un saber, ni un mètode, ni unes idees, ans de proposar un recorregut per la història personal d'un mateix. Al mateix temps, aclareix que qui dóna els exercicis, se sent empès a donar-se sense fer cap pantalla i sense procurar-se cap escut personal. Tanmateix, se subratlla que la cura personalis deixa de ser realitat quan qui dona els exercicis impedeix al que els rep conduir-se i decidir per ell mateix, perquè la cura es transforma en una direcció important o en una llavassada d'idees i d'iniciatives pròpies de l'acompanyant. Posa també en relleu el fet que

(4) Ignacio de Loyola, Ejercicios espirituales. Bilbao - Santander, Ediciones Mensajero, 2006. Aquest llibre parteix i descriu l'experiència espiritual que viu el sant. Cap el 1522, comença a escriure la seva experiència espiritual, per la qual cosa dona inici al que després serà el llibre dels Exercicis espirituals, escrit en clau pedagògica i base de l'espiritualitat i de la formació jesuítica.

(5) Les «anotacions» són notes que aclareixen el text dels Exercicis espirituals de sant Ignasi de Loiola. Per descobrir el sentit de l'expressió cura personalis ens hem deixat guiar per les «anotacions» que obren el Ilibre dels exercicis espirituals. Sembla que aquestes notes provenen d'una entrevista oral que sant Ignasi mantenia amb l'exercitant abans de començar aquests exercicis. Sant Ignasi volia precisar les característiques que havia de tenir la relació -la cura- entre l'acompanyant i l'exercitant; i en lloc de dedicar-li un tractat o un estudi exhaustiu, fa unes notes que posen en relleu els aspectes cabdals que han de formar part d'aquesta relació. 
l'autoritat de l'acompanyant ha de servir per fer «autor» l'altre, segons la mateixa etimologia del terme llatí auctoritas; ben al contrari, una actitud, una manera de ser i de fer autoritària o seductora, corre el risc de buidar del seu sentit els dos termes, tant cura com personalis.

Al llarg de tot el llibre dels Exercicis, es dona per descomptat que tot exercitant té necessitat de cura personalis i que ningú no es pot valdre per ell mateix en una situació de formació, per la qual cosa es fa necessària la figura d'un acompanyant per al seu creixement i desenvolupament. Alhora, descriu que el reconeixement i recórrer a aquest acompanyament amb generositat i llibertat és, en definitiva, ajudar-se a un mateix (EE., 5). De tota manera, el fet d'acceptar aquest acompanyament ha de culminar en la responsabilitat i en la decisió sobre els diversos aspectes de la pròpia vida.

Aquesta expressió de cura personalis es repeteix en moltes ocasions al llarg del llibre dels Exercicis -dotze vegades segons Kolvenbach (2007)- i es veu reforçada constantment per verbs reflexius que indiquen una acció que recau en el mateix subjecte del verb, com per exemple «disposar-se» (EE., 18), «corregir-se» (EE., 24) o «reflectir en mi mateix» (EE., 114), entre d'altres. Tota la dinàmica condueix, doncs, a fer la persona responsable de les pròpies decisions des de la complicitat i la responsabilitat vers els altres.

La cura personalis parteix d'una relació de confiança en la qual ha de dominar la comprensió i la benevolència; aquesta predisposició favorable tindrà la prioritat de mantenir el diàleg, la conversa o el col-loqui amb l'altre fins al final, i és important fer notar que, en la pedagogia ignasiana, l'acompanyant s'ha d'anul.lar en benefici de l'altre, de la seva llibertat i de l'afirmació i l'orientació de la seva existència.

Per bé que no és la nostra intenció aprofundir en la pedagogia ignasiana, resulta interessant copsar les coincidències existents entre aquest tret identitari de la seva formació i la necessitat de la cura personalis per a una acció educativa en què el tacte pedagògic es pugui fer present. Des de la perspectiva antropològica a què ens remet Lluís Duch (1997), copsem com ens parla de l'ésser humà com a «ésser acollit» (Duch, 1997, p. 15 i 16), en el sentit que el pas de l'ésser humà pels camins del món dependrà en gran mesura, o de manera important, de l'acollida que aquest ésser experimenti, de l'orientació que se li doni, i de la comprensió del món que pugui arribar a assolir a partir dels processos pedagògics que visqui i en els quals es veurà necessitat d'integrar-se.

Perquè en l'ésser humà s'imposen les tradicions del pensar, del sentir i de l'actuar mantingudes al llarg del temps per la seva comunitat de context. I és des d'aquesta comunitat de context que pot prendre un sentit l'acollida d'algú altre des de la cura personalis que vetlla perquè l'ésser humà arribi a la descoberta i al coneixement d'ell mateix, del seu propi món interior, i del món des del seu propi interior. Aquesta és la tasca del mestre i del formador de mestres; aquest és l'art d'educar i de formar; en definitiva, d'educar-se i de formar-se.

En una perspectiva semblant, Don Bosco (Cian, 1987) considera que educar vol dir oferir el millor terreny perquè l'infant es pugui arrelar a la seva herència familiar, social i cultural per obrir-se com un nou individu; i especifica que el millor terreny és l'alegria. L'alegria hauria de ser el clima de l'ambient educatiu. Respectar el creixement de l'infant o el jove, donar-li seguretat i responsabilitzar-lo. Donar seguretat vol dir ajudar-lo a construir una memòria de l'èxit (no recordar només el fracàs que genera una pèrdua de 
confiança en si mateix). Aquesta proposta educativa es podria situar dins d'una pedagogia de l'esperança, en el sentit que es creu i que es confia en l'ésser humà -ja sigui l'infant, el jove, el mestre o el formador- i en la seva possibilitat de creixement en humanitat i en intel-ligència.

Un altre element important que hi ha al darrere de les aportacions ètiques que han fet els grans mestres i pedagogs té a veure amb la implicació i el compromís que el mestre té $a m b$ el món -sobretot en el seu «metre quadrat»- i amb les persones ${ }^{6}$. Una implicació i un compromís que hauria de comportar una acció transformadora i de millora de les condicions del món real en el qual es duu a terme l'acció educativa. Per això cal tenir clar que la funció de l'escola és l'educació versus l'escolarització (Illich, 1976).

Tanmateix, seguint el fil de la història de la humanitat $i$, consegüentment, de la pedagogia, hi ha un moment en què tot el que hem dit s'esberla, no en queda res: és la barbàrie de l'Holocaust, de la Xoà, de la catàstrofe. I a partir d'aquest moment no podem deixar-nos de fer la següent pregunta: després del què ha passat, per què educar?, per què l'educació? Creiem que l'educació pot ajudar a la construcció de la memòria històrica de les generacions que avui s'estan formant. Caldria recordar i reconstruir el que ha passat a la llum de l'experiència històrica del nazisme, per exemple; això hauria de generar una consciència collectiva sobre la gravetat del que ha passat i crear les possibilitats perquè arreli una cultura de respecte als drets humans. Per fer-ho només podem basar-nos en el testimoniatge d'aquells que han sobreviscut a l'horror dels lager i ho han pogut narrar -Victor Frankl, Primo Levi, Anna Frank, Imre Kertész- o d'aquells dels quals $n$ 'han sobreviscut les seves obres.

Juntament amb la voluntat de no oblidar un dels actes més inhumans que han succeït al cor d'Europa durant el passat segle $\mathrm{xx}$, a les escoles i universitats hem de seguir treballant $i$ vetllant perquè els nostres estudiants conreïn unes actituds $i$ una finor espiritual que els portin a ser compassius -patir amb l'altre-, a commoure's amb l'altre, a que no restin indiferents davant de tantes i tantes situacions actuals que menystenen la dignitat humana i ens recorden massa la barbàrie de l'Holocaust. Un holocaust que avui, malauradament, se'ns presenta amb uns altres rostres i d'una altra manera, i al qual hem d'estar amatents i hem de donar resposta tal i com el Papa Francesc ens diu a la homilia de juliol de 2013 al camp d'esports Arena quan va visitar l'illa de Lampedusa en motiu del naufragi d'una barca d'immigrants. Deia el Sant Pare: «Somos una sociedad que ha olvidado la experiencia de llorar, de "sufrir con": „la globalización de la indiferencia nos ha quitado la capacidad de llorar! [...] La globalización de la indiferencia nos hace "innominados", responsables anónimos y sin rostro»".

Una víctima i testimoni de la Xoà va ser Janusz Korczak (1999), el qual va fer de la infància la prioritat de la seva vida posant-se al servei dels infants del carrer, dels orfes i dels desvalguts polonesos amb un compromís ètic i moral que el porta a acompanyarlos fins la mort des d'una acció comprensiva. Al mateix temps, posà en pràctica

(6) Bosco, Korczak, Milani són pedagogs compromesos amb el seu temps i observen la realitat concreta dels nens i dels joves pobres, explotats, abandonats, desatesos que viuen en situació de risc, i hi donen resposta amb noves propostes educatives. Molts d'ells des de l'espiritualitat cristiana o els valors evangèlics.

(7) http://w2.vatican.va/content/francesco/es/homilies/2013/documents/papa-francesco_20130708_omelialampedusa.html 
l'originalitat dels seus conceptes educatius en la tasca que desplegà en els reformatoris, els orfenats i les colònies de vacances per a nens (Korczak, 2018). Una idea fonamental del seu 'credo pedagògic' és que l'infant és un subjecte de dret, i «el nostre deure d'educadors és de permetre-li viure, de guanyar-li el dret de ser un infant» (Korczak, 1999, p. 415). Així, les seves intencions queden explicitades de la següent manera: "Quina és la meva actitud, avui, envers l'infant i la societat infantil? Responc a aquesta qüestió en el meu opuscle: El dret de l'infant al respecte» (Tort a Korczak, 1999, p. XLIX).

Podem considerar a Korczak com un dels forjadors dels drets de la infància que coneixem avui. En el marc de la Polònia assetjada pel nazisme és un dels primers en adonar-se i reclamar l'existència d'uns drets específics que són propis dels infants i també a començar a formular-los. Per això en aquest llibre es mostrarà crític respecte la 'Declaració de Ginebra sobre els drets del nen' de l'any 1924 tant pel seu to de petició com pel fet que aquesta no era vinculant pels Estats. Per això quan les Nacions Unides a l'any 1989 va promulgar la 'Convenció sobre els drets dels infants' que ja és un tractat internacional i jurídicament ja vincula als Estats, semblaria que Korczak havia aconseguit la resposta al seu reclam. Tanmateix, mai no va redactar una declaració concreta de drets dels infants, tot i que la seva obra va anar totalment encaminada a aquest repte. Tant el que diu com el que fa, tant el que escriu com les seves accions tenen aquest objectiu. En aquest sentit, en el llibre El Dret de I'Infant al respecte hi va enumerant alguns d'aquests drets, la seva consideració en el món actual i, sobretot, el paper que hi juga l'educació. No serà fins més tard, quan la seva biògrafa, Betty J. Lifton (1997) establirà una llista de drets de l'infant que es desprenen de molts dels fragments que es poden llegir en el conjunt de la seva obra.

Podem dir doncs, que el pensament i l'acció de Korczak situa en el seu l'epicentre el valor de la persona i el seu respecte -en aquest cas-, el dels infants i els joves. Segons aquest pediatre i pedagog polonès, l'infant ha de ser tractat per la persona que és avui i no per l'adult que serà demà. Ho diu així: «No es correcto decir que los niños llegaron a ser personas: son ya personas. Son personas cuyas almas contienen la semilla de todas las ideas y emociones que poseemos. Hay que orientar con delicadeza el crecimiento de esas semillas» (Lewowicki, 1994, p. 4). Tractar els infants com a éssers respectables, que pensen i que són sensibles, igual que els adults; vet aquí una idea profundament humana d'aquest gran mestre.

\section{Vers una pedagogia personalista i dialògica}

Dèiem, en començar, que tots els pedagogs han situat en el nucli de la qüestió ètica el respecte a la persona, en la seva integritat. Ara, ens detindrem en l'infant, el nen i la nena, els joves; posarem el focus damunt dels protagonistes de la relació pedagògica, igual que han fet els grans mestres. En aquest sentit, una de les implicacions ètiques a tenir present, respecte al nen i pel que fa al mestre i a la relació educativa, és que hem de tenir en compte els infants globalment, integralment; desplegant totes les seves dimensions. J. Dewey insisteix en la necessitat d'evitar els dualismes que separen la raó i el cos, el cos i l'ànima, la ment i l'acció, allò que és psicològic i allò que és social, l'individu i la societat, la teoria i la pràctica, el treball i el lleure, l'activitat pràctica i l'activitat intel-lectual, I'home i la natura (Dewey, 1985). O com diria Xirau: «Una educació total, integral i harmònica, en la qual el sentiment, el pensament i la voluntat siguin 
cultivats, alimentats, portats a la plenitud en relació amb la força activa de la vida individual» (Xirau, 1986, p. 77).

D'aquesta manera, el repte hauria de ser posar la vocació al servei dels infants i situar-los en el centre de l'acció educadora, amb el benentès que cada infant és un ésser extraordinari, complex, individual i amb els altres (Tonucci, 2004). Maria Montessori ja feia referència a aquest valor singular de l'infant i a la transcendència de l'acció educativa personalitzada quan deia que calia «respectar el ritme intern de l'ànima de cada infant» (Standing, 1985, p. 20). I també Decroly (1987) destaca la importància de veure en el fet educatiu la singularitat de l'alumne en considerar l'infant el centre de l'acció educativa i en posar en relleu que el programa pedagògic ha de ser flexible i adaptable a les característiques de cada infant. En aquesta mateixa línia, Rosa Sensat (1996) fa del respecte a l'infant i als seus interessos l'eix de la seva proposta pedagògica.

Per la seva banda, Dewey (1985) també dona gran importància a les característiques de cada infant alhora que posa de manifest que la persona només es pot entendre en interacció amb el seu entorn. Malaguzzi (2001) mostra clarament que els infants són els protagonistes de la seva pròpia història. Una citació d'Hoyuelos explicita el pensament de Malaguzzi pel que fa al respecte que ha de tenir l'escola a la singularitat de cada infant: «Es obligación ética de la escuela ofertar diversas oportunidades, que, como propuestas diferenciadas, obliguen a interpretaciones posibles que eviten caer en las etiquetas, recetas o tópicos que cierran y monopolizan el mundo de los posibles en una única dirección» (Hoyuelos, 2004, p. 207).

La formació del mestre probablement estigui més en les virtuts i no pas en les paraules. De la mateixa manera, «és difícil preparar teòricament una mestra així, que s'ha de formar ella mateixa, que ha d'aprendre d'observar, d'ésser calmosa, pacient i humil, que ha de dominar els propis impulsos, i que té una feina eminentment pràctica en la seva delicada missió. Té més necessitat d'una palestra per a l'esperit que no pas d'un llibre per a la seva intel-ligència» (Montessori, 1987, p. 170 i ss.).

Decroly explícita que l'educador ha de desenvolupar la seva professió com a persona responsable i compromesa amb el coneixement i amb les persones. En concret, ha de fer realitat l'afirmació següent: «La tasca educativa, més que qualsevol altra obra humana, ha d'ésser adaptable, plàstica, capaç d'evolució, puix que l'educador ha d'ésser per al poble. El guia intel.lectual i moral cal que estigui constantment al corrent del moviment de les idees. És a ell a qui correspon d'aprendre dels savis i dels artistes allò que han descobert o creat de bell, de gran i d'útil, per posar-ho a disposició dels homes del demà» (Muset a Decroly, 1987, XXXVII).

Seguint els ensenyaments de Don Bosco, podríem parlar d'una pedagogia de I'aliança en què el clima de l'amor obre el camí vers la confiança i amb el benentès que cal considerar el jove i l'infant com a socis de l'activitat educativa i no només com a destinataris: "Necessito que nos pongamos de acuerdo -dice Don Bosco a sus muchachos en unas "buenas noches"- y que reine entre nosotros verdadera amistad y confianza (MB 7, 504)» (Cian, 1987, p. 30 i 158). Es tractaria d'una pedagogia fonamentada en el respecte pels drets del nen i del jove. Per establir-hi aquesta relació, cal que l'educador sigui suficientment proper a fi de no ser un estrany i suficientment distant per tal de no ser considerat un igual; caldria, doncs, trobar-hi l'equilibri. Aquesta aliança també s'hauria de construir amb el grup del nen o el jove i amb els adults implicats en la 
seva educació. I això demana la implicació tant de la comunitat educativa com de la societat («societat/ciutat educadora»).

Semblantment amb el pensament de Montessori, l'infant és un ésser, amb una llibertat, una autonomia i una independència al qual només podem servir, i això vol dir guiar-lo i ajudar-lo a fi que pugui desplegar totes les possibilitats i les capacitats que té. Aquest estil de fer de mestre, com a guia i, no pas com a dirigent (Freinet, 1972), queda ben palès quan la majoria de pedagogs en reconeixen les potencialitats.

Malgrat tot el que hem dit fins ara, hi ha alguns aspectes o elements contextuals que ho dificulten, per exemple la conciliació, a voltes, difícil en la relació entre la família i l'escola pel que fa a com entenen ambdues la finalitat i els objectius educatius. Avui, en determinats ambients familiars i, fins i tot, socialment, preval una mentalitat empresarial i productiva que fomenta alguns dels valors que crèiem eradicats en l'educació com podria ser el foment de la competitivitat i de l'individualisme. L'escola ha de permetre vivenciar que és una institució social, una comunitat de vida en què cadascú té la seva responsabilitat i el seu compromís (Dewey, 1985; Vergés, 2002).

Caldria, doncs, debatre i compartir, més sovint, què significa educar i per a què. Segurament llavors hi hauria més complicitat entre la família i l'escola, i, de ben segur, aquesta complicitat influiria en el fet de reconèixer quina és la veritable raó que, avui a la nostra societat, continuï existint l'escola i que, més que mai, la professió de mestre requereixi una formació basada en l'ètica.

\section{Consideracions finals}

Per concloure, apuntem les idees següents que sintetitzen el contingut del que hem tractat al llarg de l'article. En primer lloc, la necessitat que els futurs mestres accedeixin -de manera profunda- a la descoberta de l'aportació que els grans pedagogs han fet al llarg de la història de l'educació- sobre la dimensió ètica del fet d'educar per tal de donar solidesa a la seva formació i a la futura acció educativa. I situar en el centre d'aquesta acció educativa el respecte i l'estimació a la persona. Això els ajudarà a poder legitimar la seva vocació des d'una perspectiva ètica, fonamentalment: el reconeixement a l'altre, el compromís, la responsabilitat i la cura.

En segon Iloc, el professorat universitari ha de ser conscient del seu paper en la formació ètica dels mestres. El seu testimoni és la millor garantia perquè els estudiants de Magisteri construeixin el seu perfil de mestre des dels fonaments ètics que han postulat els grans pedagogs al llarg de la història i que avui són plenament vigents i necessaris gràcies a la seva importància. D'aquesta manera s'adonaran de la transcendència que té la seva professió en la societat del segle XXI. L'educació es fonamenta en el respecte i l'estima a les persones.

En tercer lloc l'exigència d'articular un pla de formació específic en els estudis de Grau en Educació Infantil i en Educació Primària que tingui en compte explícitament aquests aspectes i que fomenti la formació del compromís ètic durant la formació inicial dels futurs mestres.

Molts dels grans mestres i pedagogs que s'han anat destacant en aquest escrit com Sant Ignasi, Xirau, Bosco, Montessori, Korzcak, Milani o Hansen, entre d'altres, elaboren els seus credos educatius com a mostra i testimoni de les seves creences religioses, la 
majoria des de la seva vocació cristiana. Probablement el testimoniatge cristià consisteixi en conrear el compromís de viure en l'amor de Déu. Tots ells són cristians enmig del món que donen testimoni de la fe vivint-la amb joia i coratge. Tots prenen consciència de la situació dels més desafavorits, s'hi comprometen i actuen amb determinació per a la transformació del seu context social i per renovar la humanitat. Aquesta presa de consciència es tradueix en una manera de ser i d'actuar envers els que més ho necessiten com a possibilitat de manifestació i de creixement del seu creure que passa per l'arrelament personal a Crist.

Semblantment a com ha dit el papa Francesc, en moltes de les seves exhortacions públiques, no s'ha de tenir por de mostrar la tendresa que cada persona té en el seu cor per oferir-la al seu germà. Això implica atrevir-se a viure l'Evangeli que vol dir acollir i tenir cura de l'altre. Sentir-se cridat per la compassió, estar atents als qui pateixen i, lliurement, fer de l'altre el nostre proïsme.

Avui en dia es continuen vivint situacions semblants a les què van viure aquells grans mestres i pedagogs. Realitats que sol.liciten de nosaltres ser també testimonis i Evangeli en acció. Com diu Rovira Belloso «La misèria i la malícia reals del món. Sabem molt bé el nom de les xacres que mantenen avui la gent sota la amenaça del mal: marginació, fam, manca d'habitatge, analfabetització, manca de cultura i d'escola, prostitució, drogoaddicció, epidèmies, injustícies sofertes pels individus i pels pobles, manca de respecte a la vida i als drets humans, violències, guerres, agressions ecològiques... Són el revers de la història» (Rovira Belloso, 1991, p. 142). Som corresponsables del que passa al nostre voltant en el moment actual.

\section{Referències}

Aristòtil (2007) Ética Nicomáquea. Traducció i notes de Julio Pallí Bonet. Introducció de T. Martínez Manzano. Barcelona, Biblioteca Clásica Gredos.

Bovet, P. (1975) El sentimiento religioso y la psicología del niño. Buenos Aires, Ed. Psique.

Casanovas, I. (1930) Sant Ignasi de Loyola autor dels Exercicis Espirituals. Barcelona, Foment de Pietat.

Cian, L. (1987) El sistema educativo de Don Bosco y las líneas maestras de su estilo. Madrid, CCS.

Decroly, O. (1987) La funció de la globalització i altres escrits. Pròleg de Margarida Muset. Vic, Eumo Editorial.

De la Arada, R.; Vilanou, C. i Carreño, A. (2014) «Lectura pedagògica de la novetat cristiana. Una aproximació a través de la filosofia de Joaquim Xirau i Octavi Fullat». Educació i Història: Revista d'Història de l'Educació, 23, p. 13-50.

Dewey, J. (1985) Democràcia i escola. Vic, Eumo Editorial.

Duch, L. (1997) La educación y la crisis de la modernidad. Barcelona, Paidós Iberica.

Freinet, C. (1972) L'educació moral i cívica. Barcelona, Ed. Laia.

Freire, P. (2005) Pedagogía del oprimido. Montevideo, Editorial Siglo XXI.

Fullat, O. (2005) Valores y Narrativa. Axiología educativa de Occidente. Pròleg de Conrad Vilanou. Barcelona, Universitat de Barcelona.

Hansen, D. (2001) Llamados a enseñar. Barcelona, Idea Books.

Hansen, D. (2002) Explorando el corazón moral de la enseñanza. Barcelona, Idea Books.

Hoyuelos, A. (2004) La ética en el pensamiento y obra de Loris Malguzzi. Barcelona, Octaedro. 
Illich, I. (1976) La sociedad desescolarizada. Barcelona, Barral Editors.

Jordán, J.A. (2015) «La responsabilitat ética-pedagògica de los profesores-educadores: una mirada nueva desde Max van Manen». Revista Española de Pedagogía, 381, p. 381-396.

Kolvenbach, P.H. (2007) Cura Personalis. Roma, CIS.

Korczak, J. (1999) Com estimar l'infant. Pròleg d'Antoni Tort. Vic, Eumo Editorial.

Korczak, J. (2018) Diario del gueto. Barcelona, Seix Barral.

Lifton, B.J. (1997) The king of children: the live and death of Janusz Korczak. New York, St. Martin's Griffin.

Lewowicki, T. (1994) «Janusz Korczak (1878-1942)». Perspectivas: revista trimestral de educación comparada. París, UNESCO: Oficina Internacional de Educación, vol. XXIV, 1-2, p. 37-48.

Loyola, I. (2006) Ejercicios Espirituales. Bilbao-Santander, Ediciones Mensajero Sal Terrae. Malaguzzi, L. (2001) La educación infantil en Reggio Emilia. Barcelona, Octaedro.

Meirieu, P. (1998) Frankenstein educador. Barcelona, Laertes.

Meirieu, P. (2001) La opción de educar. Barcelona, Octaedro.

Milani, L. (1998) Carta a una mestra. Vic, Eumo Editorial.

Milani, L. (2004) Experiencias Pastorales. Madrid, Biblioteca de autores cristianos.

Milani, L. Adieu Barbiana. Documental 60' sobre testimonis de la vida de Lorenzo Milani.

Montaigne, M. (2012) Textos sobre educació. Vic, Eumo Editorial.

Montessori, M. (1987) La descoberta de I'infant. Vic, Eumo Editorial.

Montessori, M. (1990) El niño. El secreto de la infancia. México, Ed. Diana.

Pavie, X. (2010) La méditation philosophique. Une initiation aux exercices spirituels. Paris, Groupe Eyrolles.

Piaget, J. (1969) Psicología del niño. Madrid, Morata.

Plató (1924) Diàlegs. Laques. Volum I. Barcelona, Bernat Metge.

Postman, N. (1999) El fin de la educación. Una nueva definición del valor de la escuela. Vic / Barcelona, Eumo / Octaedro.

Rousseau, J. J. (1985) Emili o de l'educació. Vic, Eumo Editorial.

Rovira Belloso, J.M. (1991) Societat i Regne de Déu. Barcelona, Cruilla.

Sensat, R. (1996) Vers l'escola nova. Vic, Eumo Editorial.

Söetard, M. (1995) «Johann Heinrich Pestalozzi». A Houssaye, J. (Dir.) Quinze pedagogs. La seva influencia, avui. Barcelona, Universitat Oberta de Catalunya-Proa, p. 44-58.

Standing, E.M. (1985) La revolución Montessori en la educación. Madrid, Siglo XXI.

Tonucci, F. (2004) Quan els infants diuen prou! Barcelona, Graó.

Trilla, J. (2002) La aborrecida escuela. Junto a una pedagogía de la felicidad y otras cosas. Barcelona, Laertes.

Van Manen, M. (1998) El tacto en la enseñanza. El significado de la sensibilidad pedagógica. Barcelona, Paidós.

Van Manen, M. (2003) Investigación educativa y experiencia vivida. Barcelona, Idea Books.

Van Manen, M. (2004) El tono en la enseñanza. El lenguaje de la pedagogía. Barcelona, Paidós.

Vergés, P. (2002) «La nostra posició pedagògica», a VVAA. L'escola nova catalana 19001936. Vic, Eumo Editorial, 2002, p. 157-162.

Xirau, M. (1986) Pedagogia i vida. Introducció de Miguel Siguan Soler. Vic, Eumo Editorial. 

cura

Resumen: Este artículo pone de relieve las aportaciones a la ética del maestro realizadas por una selección de pensadores desde la pedagogía clásica hasta la contemporánea. Se hace un repaso de la presencia de la dimensión ética en algunos textos pedagógicos de autores referentes en nuestra cultura educativa para mostrar que se trata de un tema nuclear en las aportaciones de los grandes maestros y pedagogos, del mismo modo que destaca la importancia de la ética cristiana en la pedagogía sin que ello sea excluyente de otras posibles pedagogías. A través de este recorrido se aportan elementos de reflexión y de análisis para la formación inicial de los maestros en la universidad para que esta contribución genuina de la pedagogía sea el elemento configurador del itinerario formativo del maestro.

Palabras clave: Ética, pedagogía, cuidado, acompañamiento, persona, compromiso, formación de maestros.

\section{Discours et pédagogie : un essai entre l'éthique, l'accompagnement et le "prendre soin »}

Résumé : Cet article met en relief les contributions à l'éthique de l'enseignant réalisées par une sélection de penseurs, de la pédagogie classique à la pédagogie contemporaine. L'auteur passe en revue la présence de la dimension éthique dans les textes pédagogiques d'auteurs de référence de notre culture éducative afin de montrer que cette culture est une question nucléaire entre les contributions faites par les grands enseignants et pédagogues, et de souligner l'importance de l'éthique chrétienne dans la pédagogie, sans pour autant exclure aucune autre pédagogie. À travers ce parcours, des éléments viennent alimenter la réflexion et l'analyse afin de nous aider à construire la formation initiale des enseignants à l'université et de faire de cette véritable contribution de la pédagogie un élément configurateur du parcours formatif des enseignants.

Mots clés : Éthique, pédagogie, prendre soin, accompagnement, personne, engagement, formation des enseignants.

\section{Narrative and pedagogy: an essay on ethics, accompaniment and care}

Abstract: This paper examines the contributions to teacher ethics made by a select group of thinkers ranging from classical to contemporary pedagogy. Through a review of the ethical dimension present in the pedagogical texts of the foremost authors in our educational culture, the paper identifies how this culture has been a primary concern in the contributions of great teachers and pedagogues and it highlights the importance of Christian ethics in pedagogy without excluding any other type of pedagogy. Along the way, points for reflection and analysis are raised in order to bolster early teacher training at university and ensure that this genuine contribution to pedagogy is a factor that shapes the learning pathway followed by teachers.

Keywords: Ethics, pedagogy, care, accompaniment, person, commitment, teacher training. 